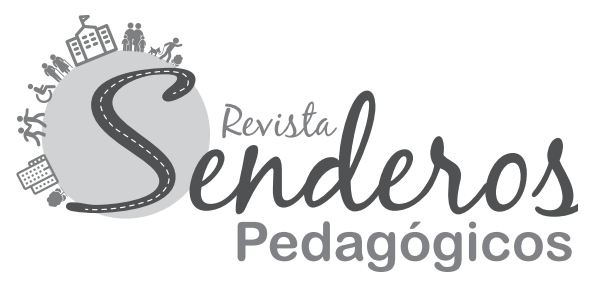

\title{
La Cartilla moral de Alfonso Reyes. Lecciones breves: preceptos de sabios ${ }^{1}$
}

\author{
Alfonso Reyes' Moral Primer. Brief Lessons: wise men's precepts
}

\author{
Autora: \\ Carolina Moreno Echeverry ${ }^{2}$ \\ Recibido: 17/06/2020 \\ Aprobado: $03 / 11 / 2020$
}

1. Este artículo es el resultado de la presentación editorial de la Cartilla moral de Alfonso Reyes. (2019). Edición y prólogo de Javier Garciadiego Opúsculos. El Colegio Nacional, México. Este evento se llevó a cabo el 24 de abril en la sala Manuel M. Ponce del Centro Cultural Jardín Borda, en Cuernavaca, Morelos; contó con la participación de: Javier Garciadiego, miembro de El Colegio Nacional; Braulio Hornedo Rocha, director de la Cátedra Alfonso Reyes en Cuernavaca; Alejandra Atala, profesora de la Universidad Autónoma del Estado de Morelos y Ángel Cuevas, funcionario de la Secretaría de Turismo y Cultura del estado de Morelos.

2. Doctora en Literatura por El Colegio de Morelos; Maestra en Literatura del Centro de Investigación en Docencia y Humanidades del Estado de Morelos (CIDHEM), México; Especialista en Hermenéutica Literaria de la Universidad Eafit. Docente de la Licenciatura en Literatura y Lengua Castellana del Tecnológico de Antioquia, Institución Universitaria. carolingiam@gmail.com

\section{Resumen:}

Desde la orientación de la literatura sapiencial, y por invitación del Secretario de Educación Pública de México, Jaime Torres Bodet, Alfonso Reyes escribe la Cartilla moral en 1944. Dividida en doce lecciones breves que incluye otras dos de síntesis, la Cartilla plantea algunos de los problemas de mayor tradición en la filosofía ética a partir de las prácticas morales: el bien y el mal, la relación entre cuerpo y alma, la conciencia, el valor y voluntad moral, la civilización y la cultura; además, expone consejos de sabiduría práctica sobre el respeto que cada ser humano se debe a sí mismo, a la familia, a la sociedad, a la ley, al derecho, a la patria, a la especie humana y a la naturaleza. Para comprender mejor la Cartilla moral es fundamental conocer las circunstancias históricas en las que se encontraban México y Alfonso Reyes para 1944; los contextos político y educativo en el momento de escritura.

Palabras clave: Cartilla moral, Alfonso Reyes, educación, pedagogía, México. 


\begin{abstract}
:
Alfonso Reyes wrote the Moral Primer in 1944 , from the orientation of the wisdom literature and at the invitation of the Secretary of Public Education of Mexico, Jaime Torres Bodet. Divided into twelve short lessons that include two other synthesis lessons, the Primer raises some of the most traditional problems in ethical philosophy based on moral practices: good and evil, the relationship between body and soul, conscience, the moral value and will, civilization and culture. It also presents practical wisdom
\end{abstract}

advice on the respect that each human being owes to himself, to the family, to society, to the law, to the right, to the homeland, to the human species, and to nature. In order to better understand the Moral Primer, it is essential to know the historical circumstances in which Mexico and Alfonso Reyes were in 1944; the political and educational contexts at the time of writing.

Keywords: Moral Primer, Alfonso Reyes, Education, Pedagogy, Mexico.

Desde la orientación de la literatura sapiencial —en la que el padre, maestro o preceptor inculca al hijo, discípulo o educando los consejos de conducta y exhorta a su ininterrumpida transferencia de generación en generación-, Alfonso Reyes escribe la Cartilla moral en 1944. Por invitación del Secretario de Educación Pública, Jaime Torres Bodet, el escritor mexicano compone el libro entre el 15 y 17 de septiembre. Dividida en doce lecciones breves que incluye otras dos de síntesis, la Cartilla plantea algunos de los problemas de mayor tradición en la filosofía ética a partir de las prácticas morales: el bien y el mal, la relación entre cuerpo y alma, la conciencia, el valor y voluntad moral, la civilización y la cultura; además, expone consejos de sabiduría práctica agrupados de tal manera que puedan ser recordados, desde el más individual hasta el más general, desde el más personal hasta el más impersonal, tales como: el respeto que cada ser humano se debe a sí mismo, a la familia, a la sociedad, a la ley, al derecho, a la patria, a la especie humana y a la naturaleza.

Para comprender mejor la Cartilla moral, "libro más elogiado que leído", como bien recuerda Javier Garciadiego en su estudio introductorio de la reciente edición publicada por El Colegio Nacional (2019), es fundamental conocer las circunstancias históricas en las que se encontraban México y Alfonso Reyes para 1944, esto es, los contextos político y educativo en el momento de escritura. 


\section{La lucha contra el analfabetismo de la Secretaría de Educación Pública}

Una de las principales tareas de las que se ocupó Jaime Torres Bodet, tercer titular de la Secretaría de Educación Pública (SEP) ${ }^{3}$, durante la administración del presidente Manuel Ávila Camacho (1940-1946), fue la preparación de la Ley de emergencia en la que se sustenta jurídicamente la Campaña Nacional contra el Analfabetismo. El 21 de agosto de 1944, el presidente firmó la ley que imponía a cada mexicano, entre 16 y 60 años que supiera leer y escrbir, la obligación moral de enseñar a un analfabeto entre los 6 y 40 años. El director general de la Campaña sería el presidente de la República, y su director ejecutivo, el secretario de Educación. En la locución radial de ese mismo día, el general Ávila Camacho declara:

Sé muy bien que la educación de un pueblo no radica exclusivamente en eliminar el analfabetismo. Pero sé, con igual claridad, que el primer paso indispensable es enseñar a leer y a escribir y que, mientras la mitad de los mexicanos esté compuesta por iletrados, ninguno de los otros programas sociales que confrontamos podrá ser planteado con la esperanza de una completa y lógica solución. [...] Exhorto (a todos los mexicanos que han recibido los beneficios de la enseñanza) para que se apresten a la campaña que proponemos a su entusiasmo y a su sentido del deber. Yo mismo participaré en esta labor. Y, junto conmigo, todos mis colaboradores. Y, junto con nosotros, nuestras esposas. Y no acepto creer que haya un compatriota que, pudiendo ayudarnos en esta empresa, se resista a hacerlo por egoísmo (Torres Bodet, 2017, pp. 464-465).

Según los datos del Sexto censo de población de 1940 (INEGI, 2019), de los casi veinte millones de habitantes de México, poco más de dieciséis millones tenían más de seis años, y de ellos, casi nueve millones no sabían leer ni escribir. De la población mayor de seis años, el 91\% (casi quince millones) declaró no recibir ningún tipo de instrucción. Otro dato revelador de la situación educativa del país era que para la educación básica, incluidas secundaria y prevocacional, la instrucción recibida era solamente del 7,9\%; mientras que la educación media, técnica y superior universitaria apenas llegaba al 0,55\% (Hornedo Rocha, 2019).

Aunque en el Plan sexenal del presidente Ávila Camacho se había contemplado la idea, el más relevante promotor de la Campaña Nacional contra el Analfabetismo fue Jaime Torres Bodet, gran conocedor del sector educativo del país,

3. El primer Secretario de Educación Pública durante la presidencia del general Manuel Ávila Camacho fue el abogado, militar y político poblano Luis Sánchez Pontón, quien ocupó el cargo desde el 1 de diciembre de 1940 hasta el 12 de septiembre de 1941; el segundo fue el abogado y militar veracruzano, Octavio Vejar Vázquez, desde el 14 de septiembre de 1941 hasta el 20 de diciembre de 1943; el tercero fue el poeta, escritor y diplomático Jaime Torres Bodet, desde el 23 de diciembre de 1943 hasta el 30 de noviembre de 1946 (Secretaría de Educación Pública del Gobierno de México, 2019). 
ya que había sido uno de los más cercanos colaboradores de José Vasconcelos; quien, como rector de la Universidad Nacional en 1920, y posteriormente como secretario de Educación Pública entre 1921 y 1924, reorganizó y modernizó la educación en México. Su propuesta otorgó un papel fundamental a los maestros e intelectuales para que trabajasen como "misioneros" del gran proyecto de regeneración nacional. El llamado al patriotismo, la abnegación y la solidaridad tuvo gran eco entre estudiantes, jóvenes de clase media, mujeres, profesores, trabajadores de sindicatos y gremios sociales; hizo de los maestros, un ejército de paz; de los intelectuales, "apóstoles de la educación” (Vasconcelos, 1923, pp. 177-178). Siguiendo los pasos de Vasconcelos, Torres Bodet ratifica veinte años después la lucha voluntaria contra el analfabetismo; con entusiasmo declara: “[1]as misiones rurales habían practicado esa lucha, durante años. Por eso mismo, me pareció conveniente encontrar un procedimiento capaz de dar a la antigua idea un carácter nuevo, de urgencia, de actualidad y de cívica obligación" (2017, p. 417).

La Campaña Nacional contra el Analfabetismo se dividió en tres etapas: la de “organización", desde la fecha de expedición de la Ley de emergencia hasta el último día de febrero de 1945; la de "enseñanza”, desde el 1º de marzo de 1945 hasta el último día de febrero de 1946; y la de "revisión y exposición de resultados", desde el $1^{\circ}$ de marzo de 1945 hasta el 31 de mayo de 1946 (Exposición, 1984, p. 290).

Si bien esta Ley obliga a que cada mexicano letrado enseñe a leer y escribir al menos a un compatriota, las condiciones materiales pronto dejaron ver las dificultades para instrumentar esta responsabilidad. No bastó la propaganda desarrollada por el gobierno en la prensa y la radio para vencer la apatía de diversos sectores de la población. La Secretaría de Educación Pública decidió entonces imprimir diez millones de cartillas para la enseñanza de la lectura y escritura en español, con el apoyo de las rotativas de los principales diarios nacionales. Además, Torres Bodet se percató que las virtudes de los maestros no se improvisan y fue orientando los esfuerzos de la Campaña Nacional contra el Analfabetismo a la creación de "centros de enseñanza colectiva”, en donde los ciudadanos obligados, reuniesen sus esfuerzos y sus pupilos en dichos "centros":

Para ellos, para sus compañeras, para sus hijos, íbamos a editar, por millones una cartilla. ¿Qué mensaje podríamos transmitirles en esas páginas dedicadas principalmente a ejercicios sencillos, de identificación de letras, formación de sílabas, integración de palabras cortas en frases breves e inteligibles? [...] La bondad, el valor, la voluntad de progreso, la confianza en la libertad, el amor a la patria y la solidaridad con todo el género humano son fuerzas laicas insobornables [...] Sin embargo, con la savia de aquellas fuerzas tendríamos que nutrir el mensaje moral de nuestra cartilla. ¿Cómo hacerlo entender a sus redactores? (Torres Bodet, 2017, p. 470). 
Queda manifiesta la preocupación de Torres Bodet sobre los valores morales que se deben transmitir a los alfabetizados: "La bondad, el valor, la voluntad de progreso, la confianza en la libertad, el amor a la patria y la solidaridad con todo el género humano". Pero, ¿cómo compaginar y hacer comprender estos elaborados conceptos a un lector incipiente, recién alfabetizado y de muy baja comprensión lectora? Además de la "cartilla alfabetizadora”, era necesaria una "cartilla de principios morales”. Para llevar a cabo esta propuesta, Jaime Torres Bodet solicita el apoyo de Alfonso Reyes.

\section{La historia editorial de la Cartilla moral}

El 14 de septiembre de 1944, José Luis Martínez, secretario particular del titular de la Secretaría de Educación Pública, le escribe a Alfonso Reyes para proponerle "una tarea que posiblemente le parezca ardua”. Le informa que además de la cartilla para enseñar a leer y escribir que se usará en la Campaña Nacional contra el Analfabetismo, se necesita una "cartilla de instrucciones", "un mínimo de principios morales" para poder construir los "cimientos de una nación moderna, espiritual, moral y materialmente rica” (Garciadiego, 2019, pp. 119-120).

Reyes acepta el encargo. En la entrada del 15 de septiembre, registra en su Diario: “[1]a Secretaría de Educación Pública me invita a escribir las lecciones de moral para las cartillas de la campaña del alfabeto". Para el 16 de septiembre, relata que junto con su esposa Manuela Mota y la mayor de sus nietas, Tikis (Alicia Reyes), escuchan el "Grito de Independencia” por radio; la nota del día concluye: "[e]stoy escribiendo ya las Lecciones de moral para la Cartilla alfabética". El 17 de septiembre menciona: “[a]cabé la Cartilla moral”. Reyes llama a José Luis Martínez para mostrarle lo hecho y constatar si corresponde a las expectativas del secretario Torres Bodet (Diario 1939-1945, 2018, pág. 450).

Durante estos primeros días de septiembre, Alfonso Reyes celebra también la publicación de El deslinde: prolegómenos a la teoría literaria, libro canónico sobre el "pensar literario"; además de Tentativas y orientaciones, colección de ensayos y discursos de vocación americanista. Finaliza además los detalles para la segunda edición de Ifigenia cruel, poema dramático considerado un clásico de las letras mexicanas; entrega a las ediciones de El Colegio de México ${ }^{4}$ Capítulos de literatura española. Segunda serie, compilación de estudios filológicos, escritos entre 1917 y 1943; tiene preparados para copiar en limpio cinco libros más: Astillas, A lápiz, Los trabajos y los días, La vega y el soto, Norte y sur; y prepara el curso sobre cultura helénica para El Colegio Nacional 5 . Esta ardua labor intelectual la lleva a cabo a pesar de seguir convaleciente de un resfrío adquirido por los ciclones en el Golfo, y se consuela al recibir con cierta fundada esperanza las noticias de la toma de Bruselas y la entrada en

4. Institución pública de carácter universitario que preside desde 1940.

5. Institución pública dedicada a la divulgación de la cultura científica, artística y humanística a la que pertenece desde 1943. 
Amberes y París de las tropas de los aliados en el frente europeo durante la Segunda Guerra Mundial (Diario 1939-1945, 2018, pp. 446-450).

Posterior a la entrega de la Cartilla moral, el 19 de septiembre José Luis Martínez acude nuevamente a Reyes para que revise la "cartilla alfabetizadora" que se utilizará en la Campaña Nacional contra el Analfabetismo. Le envía el único ejemplar disponible. Para el 20 de septiembre, Reyes envía las correcciones del ejemplar, que al ser único, lo considera un "borrador". Recomienda:

superar los silabarios; citar a algún clásico de las letras mexicanas en vez de citar las "palabras tan transitorias" de un presidente; corregir los errores de puntuación, acentuación y redacción: "para el preceptor faltan los :, el ( ) y las “”, y la cursiva. En el alfabeto dibujado, falta la letra Uu. En el a máquina falta la letra Z. [...] En español, hay que acentuar las mayúsculas"; mejorar el orden de la serie de las vocales: A E I O U, no I U E O A (Garciadiego, 2019, pp. 123-124).

Dadas las correcciones sugeridas a la Secretaría, Alfonso Reyes se inquieta. En la noche del 20 de septiembre escribe:

No duermo pensando en los errores de la cartilla alfabética. Muy de mañana, voy a despertar a José Luis Martínez, a quien comunico mi inquietud por lo mal que está ese proyecto. [...] Me siento nerviosísimo. Poco después, José Luis pasa por El Colegio y me recoge mi Cartilla moral y las dos lecciones resumidas (Diario 19391945, 2018, pp. 452-453).

Sin embargo, la respuesta nunca llega. Reyes no conoció las razones de Torres Bodet para no publicar el texto que le había encomendado. A propósito de la “cartilla de principios morales”, el entonces secretario de Educación Pública menciona en sus Memorias:

Realizamos varios intentos, todos estériles. Se me presentaban textos bien meditados, pedagógicamente correctos, pero fríos, inertes, y demasiado sumisos a una sola técnica de enseñanza: o la tradición, o - al contrario- la modernidad "globalizadora" [...]. Urgía una cartilla de tipo ecléctico que sirviese tanto a los profesores recién salidos de alguna Escuela Normal cuanto a los espontáneos de la enseñanza, inhábiles y bisoños, pero deseosos de cumplir el deber que la Ley de emergencia les prescribía. Por otra parte, convenía que algunas lecciones de la cartilla —las que figurasen en sus últimos pliegos - iniciaran un diálogo cívico: el que estimábamos necesario para robustecer la unión de los mexicanos. 
Seguí buscando, entre los maestros. Y di, por fin, con una mujer que advirtió claramente mis intenciones. Inscribo su nombre aquí, no sin gratitud. Es el de la profesora Dolores Uribe. Ella y la profesora Carmen Cosgaya Rivas, tomaron a su cargo la preparación de la cartilla (Torres Bodet, 2017, p. 470).

Aunque todo parecía indicar que las lecciones morales permanecerían inéditas, Alfonso Reyes las rescata del olvido. A propósito del ofrecimiento de Daniel Cosío Villegas, director del Fondo de Cultura Económica (FCE) desde su creación en 1934, para editar sus obras completas el 21 de agosto de 1947, Reyes se dedica a organizar su producción. Al preparar los índices de los trabajos en marcha, recupera la Cartilla moral para incluirla en una colección titulada "Palustre". Según Javier Garciadiego, a esta "paleta de albañil” Reyes la había nombrado originalmente como "Archivo" (2019, p. 19).

Aunque Cosío Villegas se mostró evasivo ante el plan editorial propuesto, otro intento de ordenación ocurre en 1952. El 20 de marzo, con ayuda de Raimundo Lida $^{6}$, el escritor mexicano trabaja en la organización de los documentos para su Antología historia de mis libros. Producto de esta nueva clasificación, imprime el 18 de julio la Cartilla moral en un tiraje de apenas doscientos ejemplares, como parte de la Serie C (Residuos) de su “Archivo", destinado a ser distribuido como obsequio entre sus amigos.

El cambio de fortuna de las lecciones morales ocurre para 1958, cuando Rosario Castellanos y Gastón García Cantú, responsable de las publicaciones del Instituto Nacional Indigenista (INI), le proponen a Reyes efectuar una edición masiva. El escritor mexicano ajusta la versión de 1944 y en el "Prefacio" advierte que las “[...] lecciones fueron preparadas al iniciarse la 'campaña alfabética’ y no pudieron aprovecharse entonces”. Agrega además que “[...] están destinadas al educando adulto, pero también son accesibles al niño"; no obstante, en uno y otro caso "suponen la colaboración del preceptor, sobre todo para la multiplicación de ejemplos”. Reyes solicita la participación activa de educadores y educandos para la interpretación adecuada de las lecciones morales. Para el 2 de junio de 1959, siete meses antes de morir, el escritor mexicano recibe los primeros 17 ejemplares de la primera edición masiva de su Cartilla moral (Garciadiego, 2019, pp. 21-23).

Después del fallecimiento de Alfonso Reyes, la historia de la Cartilla moral ha continuado escribiéndose. Según las investigaciones histórico bibliográficas de Javier Garciadiego (2019, pp. 9-42), entre las ediciones más relevantes se encuentran: 1962: Instituto Nacional Indigenista (INI); 1979: tomo XX de las Obras completas de

6. Con Alfonso Reyes, creó el Centro de Estudios Literarios de El Colegio de México. 
Alfonso Reyes, edición a cargo del FCE7; 1982: Asociación Nacional de Libreros, a propósito de la celebración del Día Nacional del Libro; 1989: Partido Revolucionario Institucional (PRI) y Secretaría de Educación y Cultura de Nuevo León, Monterrey; 1992: Secretaría de Educación Pública (SEP); 1994: edición de Alianza EditorialConaculta; 2004: colección Centzontle del FCE; 2005: Universidad Autónoma de Nuevo León; 2008: Universidad Autónoma de Nuevo León-Universidad Autónoma de Baja California; 2018: SEP; 2019: colección Ocúspulos, El Colegio Nacional y Universidad Autónoma de Nuevo León (ediciones publicadas en el marco de los 75 años de creación de la Cartilla moral, del 130 aniversario del natalicio de Alfonso Reyes y de los 60 años de su partida).

\section{La propuesta didáctica alfonsina}

Para facilitar el entendimiento de la Cartilla moral, Alfonso Reyes sugiere que las doce lecciones breves que incluyen otras dos de síntesis, se imaginen como una serie de círculos concéntricos, empezando por el interior hasta ir abordando el círculo más amplio. Las primeras cuatro plantean algunos de los problemas de mayor tradición en la filosofía ética: el bien y el mal, la relación entre cuerpo y alma, la conciencia, el valor y voluntad moral, la civilización y la cultura; las lecciones cinco a la doce incluyen consejos sobre el respeto que cada ser humano se debe a sí mismo, a la familia, a la sociedad, a la ley, al derecho, a la patria, a la especie humana y a la naturaleza.

La Cartilla moral, homilía en la que Reyes da cuenta de su instinto y disciplina clásicas, es en su opinión, el texto "más auténticamente griego" que escribió en su vida, como bien recuerda en su Diario el 25 de septiembre de 1958 (Diario 1951-1959, 2015, p. 673). Ni tímidamente inclinado sobre Grecia, sino por el contrario involucrado en ella a su manera, el escritor mexicano frecuentó la "afición de Grecia” con renovado ímpetu en la aventura del pensar. Todos los aspectos de la cultura helénica fueron de su interés: filosofía y literatura, geografía e historia, mitología y religión; bien sea en investigación y creación, bien sea en divulgación y exposición, Reyes contribuyó a avivar el espíritu de las humanidades clásicas en México. Prueba de ello son los siete tomos, entre los veintiséis, de las Obras completas publicados por el FCE: XIII. La crítica en la edad ateniense, La antigua retórica; XVI. Religión griega, Mitología griega; XVII. Los héroes, Junta de sombras; XVIII. Estudios helénicos, El triángulo egeo, La jornada aquea, Geógrafos del mundo antiguo, Algo más

7. A partir de 1979, la Cartilla moral ha sido integrada en diversas antologías de autor, para así convertirse en un texto relevante dentro de la vastísima producción alfonsina. Entre las antologías más relevantes se encuentran: 1979, Ernesto Mejía Sánchez: Antología, Promexa; 1997, Alfonso Rangel Guerra: Recoge el día. Antología temática, 2 t., El Colegio Nacional; 2010, Alberto Enríquez Perea: Alfonso Reyes, Cal y Arena; 2015, Javier Garciadiego: Alfonso Reyes, "un hijo menor de la palabra", FCE (Garciadiego, 2019, p. 39). 
sobre los historiadores alejandrinos; XIX. Los poemas homéricos, La Ilíada, La afición de Grecia; XX. Rescoldo de Grecia, La filosofía helenística, Libros y libreros en la Antigüedad, Andrenio: perfiles del hombre, Cartilla moral; XXI. Los siete sobre Deva, Ancorajes, Sirtes, Al yunque, A campo traviesa.

Con el ánimo de que la Cartilla moral sea más comprensible para los lectores, Reyes insiste en la explicación. El conjunto de conocimientos teóricos y prácticos enunciado es sencillo. El escritor mexicano procuró que las oraciones y párrafos se relacionaran unos con otros, para que el lector pudiera ir vinculando el discurso con el tejido de conceptos expuesto. Al dejar de lado el "enojoso tono exhortatorio" característico de las doctrinas morales — como es el caso de la moral católica, laicista o protestante, por tan solo mencionar algunas - pretendió que las lecciones fueran amenas. De tal forma, los preceptos de conducta, "de validez universal para todos los pueblos y para todos los hombres" son expresados a partir de conceptos, teorías generales, ejemplos de orden práctico, citas y alusiones a los autores clásicos (2019, pp. 69-72).

Así, en la "Lección I" determina lo que no es el bien, para luego llegar a la proposición específica. Dice Reyes: el bien "no debe confundírselo con nuestro provecho, nuestro gusto o nuestro deseo". Más adelante agrega que algunos han considerado que solo puede conocérsele a partir de la razón, y que, por lo tanto, “[...] no se puede ser bueno si, al mismo tiempo, no se es sabio"; punto de vista que se complementa cuando afirma: “[...] otros consideran que el bien se conoce por el camino del sentimiento y, como la caridad, es un impulso del buen corazón, compatible aun con la ignorancia”. Después enuncia: “[e]l bien es el conjunto de nuestros deberes morales" (Cartilla moral, 2019, p. 73). Reyes analiza los niveles del obrar humano para aseverar, tal como lo hace Aristóteles en su Ética a Nicómaco, que el cumplimiento del bien debe encaminar la conducta del hombre.

$\mathrm{Al}$ ofrecer un ordenamiento descriptivo, el escritor mexicano se aproxima a las teorías éticas para comprender el fenómeno de la moralidad. En el caso de la relación entre cuerpo y alma, objeto de reflexión de la "Lección II”, Reyes comienza dividiendo la cuestión en tres aspectos: origen de la dualidad, el cuerpo y el alma; para luego indicar que lo que debe procurarse es una prudente armonía entre ambas entidades: "[1]a tarea de la moral consiste en dar a la naturaleza lo suyo sin exceso, y sin perder de vista los ideales dictados por la conciencia. Si el hombre no cumple debidamente sus necesidades materiales, se encuentra en estado de ineptitud del espíritu y para realizar los mandamientos del bien” (Cartilla moral, 2019, p. 76). Toda conducta del hombre se presenta como disyuntiva: hacer esto o hacer lo otro; disyuntiva que Reyes aprovecha para rememorar el mito del carro alado de Platón. En esta narración alegórica del Fedro, el alma es representada por un coche conducido por un auriga y accionado por dos caballos: el primero representa la prudencia y moderación; el segundo, la desmesura y vanidad. En consecuencia, el 
fundamento para conducirse moralmente es una adecuada deliberación, es decir, un uso apropiado de la razón.

Con respecto al vínculo entre civilización y cultura, tema central de la "Lección III", Reyes establece las simpatías y diferencias entre ambos términos. Por civilización comprende “[...] el conjunto de conquistas materiales, descubrimientos prácticos y adelantos técnicos de la humanidad"; por cultura, "las conquistas semejantes de carácter teórico o en el puro campo del saber y del conocimiento, así como las creaciones artísticas”. Para el escritor mexicano, la civilización y cultura coinciden en los conocimientos teóricos, las aplicaciones prácticas y las creaciones artísticas inspiradas por "la voluntad moral o de perfeccionamiento humano" (Cartilla moral, 2019, p. 78-79).

La cultura es una construcción histórica en el que ideas y prácticas se relacionan; no es un atributo de hombres aislados, sino de hombres en sociedad; representa las conquistas por medio de las cuales el ser humano puede ser lo que es, y mejor aun lo que ha de llegar a ser. Empero, para que tal unificación se establezca, debe ser transmitida. La transmisión de la cultura en el orden del espacio comunica a los coetáneos; en el orden del tiempo comunica a las generaciones de contemporáneos y conforma una tradición. Sin este doble proceso, insiste Reyes, no hay cultura posible (Posición de América, 1997, p. 257).

En la "Lección IV", la noción de "respeto" ocupa un lugar central en el discurso alfonsino: la valoración del bien, asunto de la moral, implica el acatamiento de una serie de "mandamientos" que son inapelables. A partir de la noción kantiana del deber, Reyes establece que la moralidad de una acción humana no se puede fundamentar en su "materia", en los bienes o fines a los que tiende una acción: "para obtener ésta o la otra ventaja práctica, o para ganar éste o el otro premio"; sino en su "forma", esto es, en la intención del hombre, teniendo en consideración que esta intención trae consigo una "satisfacción moral". Realizar una acción solo por inclinación no es moral, aunque esté conforme con el deber; no se trata solo de obrar de acuerdo con el deber, sino por el deber. De este modo, al reconocer un bien superior a nuestro bien particular e inmediato, se asegura “[...] la subsistencia de la especie, la perduración de la sociedad, la existencia de los pueblos y de los hombres" (Cartilla moral, 2019, pp. 81-82).

A partir de la "Lección V" hasta la "Lección XI", Reyes describe los siete respetos morales que han sido universalmente aceptados. En esta serie de apartados establece cómo el instinto natural debe complementarse con la educación moral, con la cultura y con la adquisición de conocimientos; para actuar no es suficiente la buena intención. Para cada uno de los siete "mandamientos" determina ejemplos de orden práctico buscando facilitar la comprensión, el aprendizaje y su posterior aplicación en la vida diaria.

Debido a que la moral establece una serie de respetos, contenidos unos dentro de otros, que van desde el más próximo hasta el más lejano, Reyes enuncia "El respeto 
a nuestra persona, en cuerpo y alma”. En la “Lección V”, determina que la veneración al cuerpo enseña a ser limpios y moderados en los apetitos naturales; el miramiento al alma comprende las virtudes de orden espiritual. Apelando a consejos específicos, el escritor mexicano recomienda, por ejemplo: cumplir con las necesidades corporales con decoro y prudencia, la limpieza de las intenciones y el culto a la verdad; asegurar el buen funcionamiento del espíritu a partir del descanso, el esparcimiento, el juego y el buen humor, puesto que la capacidad de alegría es una "fuente del bien moral" (Cartilla moral, 2019, p. 85). Ambos respetos al cuerpo y alma propician, así como los griegos los nombraron, el aidós, sentimiento de la propia dignidad y la némesis, estado afectivo de justa indignación ante las indignidades ajenas.

“El respeto a la familia" es motivo de reflexión de la "Lección VI". La familia tiene consecuencias morales en el carácter del hombre. Como ejemplo de orden práctico, Reyes recuerda que el hogar es la primera escuela: debe haber respeto de los hijos para con los padres y de los menores para con los mayores, así como entre hermanos. Los progenitores deben respetar a sus descendientes, procurándoles solo dignos ejemplos. Para asegurar una vida civilizada, empiezan a aparecer las obligaciones recíprocas: por un lado, los derechos o facultades que se pueden exigir y, por el otro, los deberes o exigencias morales de corresponder a los otros. Este cambio o transacción es “[...] lo que hace posible la asociación entre hombres”. Y así como el hombre al nacer es parte de una familia, las familias al agruparse conforman tribus, estas a su vez se organizan en naciones, y tal es el origen de nuestros pueblos. De tal modo que "[...] no hay persona sin sociedad, ni sociedad sin personas" (Cartilla moral, 2019, pp. 90-92). Empero, la forma en que el grupo se organiza, lo que se conoce como Estado, cambia y se transforma en la historia: autocracia, aristocracia, democracia; monarquía absoluta, monarquía constitucional, república. Al mencionar las formas del ejercicio del poder, el escritor mexicano enuncia los diversos modos de organización política de los pueblos.

"El respeto a la sociedad" es objeto de la "Lección VII". El respeto al conjunto de personas, pueblos y naciones es lo que hace posible la convivencia. Toda acción humana se ve reflejada en la polis y redunda para bien o para mal en el entendimiento entre los hombres. Por tal razón, Reyes establece que el empeño de llevar la realidad hacia un estado más maduro, es a final de cuentas el esfuerzo característico de la política. Y es desde esta orientación que se devela la voluntad de concordia que se orienta hacia el triunfo de aquellas normas que exaltan al hombre en cuanto a lo que tiene de excelsamente humano:

Todos los pueblos nos merecen igual respeto; y por respeto a todos los pueblos, por respeto a la humanidad, deseamos el triunfo de aquella filosofía política que ofrece la libertad con la justicia, la coherencia entre la persona y la sociedad, y no el triunfo de la que sólo exhibe los anhelos de venganza y explosiones de odio (Esta hora del mundo, 1997, p. 253). 
Teniendo en consideración que los respetos sociales son de varias categorías, según sean indispensables a la subsistencia de la sociedad, el escritor mexicano establece que el primer grado o categoría del respeto social obliga a la urbanidad y a la cortesía; aconseja: el buen trato y las maneras agradables; evitar la grosería y el uso del tono violento y amenazador, sino en último extremo; recordar que hay igual o mayor bravura en dominarse a sí mismo que en agraviar al prójimo (Cartilla moral, 2019, p. 94).

El segundo grado del respeto social se refiere a la sociedad organizada en un Estado, en un gobierno con sus propias leyes. "El respeto a la ley y el derecho", tema de la "Lección VIII", asume a su vez varias categorías. Aquel que contravenga la ley debe sufrir igual pena, sea poderoso o débil, rico o pobre. Son verdaderos castigos: indemnización, multa, destitución, prisión, entre otras puniciones, según sea la legislación aplicable y la gravedad del acto violatorio. El derecho "procura establecer la justicia en todos los tratos y compromisos entre los hombres" (Cartilla moral, 2019, p. 96). En este sentido, todo delito es también una falta a la moral; sin embargo, hay violaciones morales que no se constituyen en violaciones jurídicas. Así, se establecen diferentes niveles del derecho, es decir, los distintos caracteres de los respetos que la ley determina a partir de sanciones y castigos. Por ejemplo, incumplir un contrato supone una indemnización; robar, agredir o matar al prójimo implican penas mayores, que van desde la multa a la cadena perpetua o la muerte.

“El respeto a la patria”, propósito de la "Lección IX”, debe ir acompañado del amor al propio país, a la confianza en sus futuros destinos. Este sentimiento de patriotismo debe impulsar al hombre a mejorar su nación, aun en aquellas circunstancias en que no se lo demanden las leyes. Más allá de los ideales religiosos, humanísticos o racionalistas, se debe propender por fomentar la vecindad entre los hombres.

La comprensión entre las naciones y profesar el ideal de paz favorecen el progreso moral de la humanidad: "[l]a paz es el sumo ideal moral. Pero la paz, como la democracia, sólo pueden dar sus frutos donde todos la respetan y aman”. Para que tal armonía entre los pueblos no sea vulnerada, el escritor mexicano precisa que, mientras haya un solo país que aspire a conquistar a las demás naciones, el verdadero pacifismo consiste en establecer alianzas y armarse para impedir este tipo de delito internacional. Del mismo modo, cuando en un país libre, los enemigos de la libertad arremeten en contra de esta libertad, haciendo uso de las mismas leyes que les permiten expresar sus ideas y prácticas siniestras, el espíritu de la libertad demanda sanción y castigo (Cartilla moral, 2019, p. 99-101).

Y así como el respeto a la propia persona obliga al respeto para el prójimo; el respeto a la familia impone el respeto a la sociedad; el respeto a la patria lleva al respeto por las demás naciones; tales acatamientos se orientan, por lo tanto, al "Respeto a la especie humana", principio analizado en la "Lección X". Este tipo de veneración implica el "amor a los adelantos ya conquistados, amor a sus tradiciones y esperanzas de mejoramiento” (Cartilla moral, 2019, p. 102). 
La tradición establece la continuidad del impulso unificador de la cultura en el tiempo, asegurando el aprovechamiento de las anteriores conquistas por las nuevas generaciones. Es un movimiento de perfecta relación histórica: se afianza sobre el pasado, recogiendo las aportaciones que dan los siglos de manera tal que se utilice como resorte del presente y salte así "con robusta confianza sobre el mar movible del porvenir” (Atenea política, 1997, p. 195). El escritor mexicano aconseja que las buenas obras de la humanidad deben ser respetadas por todos los hombres. Se debe evitar, por ejemplo, causar detrimento, menoscabo o perjuicio a la propiedad ajena por el gusto de hacerlo; revelan, en quien los acomete, una inconsciencia que le impiden considerar todo el esfuerzo que conlleva cada obra humana.

El acatamiento más impersonal de los respetos morales, el círculo más general de los círculos concéntricos que enuncian los "mandamientos" de la Cartilla moral es el "Respeto a la naturaleza", precepto de la "Lección XI". Esta deferencia no es un respeto absoluto a la naturaleza por ella misma, sino una exigencia que se impone al hombre para asegurar su supervivencia en la tierra. La naturaleza, "morada humana, el escenario de nuestra vida” (Cartilla moral, 2019, p. 105), debe ser protegida por ser patrimonio de la humanidad; asimismo, las especies animales y vegetales merecen toda la atención e inteligencia en su cuidado y preservación. Para Reyes el espíritu de la maldad aflora por ejemplo cuando, por gusto, enturbiamos un depósito de agua potable, matamos animales sin necesidad y fuera de los casos en que los empleamos como alimento.

La "Lección XII” comienza enunciando que, así como hay cosas que dependen del hombre, hay otras cosas que no dependen de él. A partir del "principio de la vida serena”, postulado por Epicteto en el Enquiridión, Reyes explica lo que escapa al poder de los hombres. Ello puede ser de orden emocional, como la amargura o el sufrimiento inevitables en toda existencia humana; o de orden intelectual, como la verdad que en ocasiones hasta puede contrariar nuestros deseos o intereses; o de orden físico, como un rayo o un terremoto. El escritor mexicano hace énfasis en que sin un mínimo de respeto para lo que escapa a la voluntad humana, nuestra vida sería imposible; recuerda además que tal resignación es una parte de la virtud. El compenetrarse con los respetos morales conlleva a "conquistar el valor moral y la serenidad entre las desgracias y los contratiempos" (Cartilla moral, 2019, p. 109); cualidad fundamental del "hombre de temple”, que sabe aceptar las desgracias sin que por ello se considere perdido.

Y así como en cada una de las lecciones se han utilizado los conceptos, las teorías generales, los ejemplos de orden práctico para facilitar la comprensión de los “mandamientos morales", Reyes usa también las citas y alusiones para que los lectores vayan despertando el gusto por la cultura y pierdan el miedo a los clásicos, "[...] base indispensable de nuestra educación y en los que hay que insistir cada vez más” (Cartilla moral, 2019, p. 70). Las referencias a Sócrates, Platón, Aristóteles, Horacio, Epicteto, Dante Alighieri, Immanuel Kant, Rudyard Kipling, Amado Nervo y Enrique González Martínez determinan que en cada texto se establece un conjunto de relaciones voluntarias o involuntarias, explícitas o implícitas con otros textos. 
Los clásicos son fuentes inagotables de historia; de valiosos ejemplos que siempre han inspirado a los hombres; de nombres propios que, a fuerza de repetirlos, poseen ya el poder de remover lápidas en los sepulcros; de ideas y acciones con cuyo contraste se miden las virtudes de los hombres. En una sola página de la Eneida, recuerda Reyes, la heroicidad de talla humana, descrita por Virgilio, sirve de senda medida para los hombres de todas las tierras: "En las aventuras del héroe que va de tumbo en tumbo salvando los Penates sagrados, sé de muchos, en nuestra tierra, que han creído ver la imagen de su propia aventura, y dudo si nos atreveríamos a llamar buen mexicano al que fue capaz de leer la Eneida sin conmoverse" (Universidad, política y pueblo, 1967, p. 47).

\section{Para concluir}

Alfonso Reyes busca "partear" las vocaciones en la Cartilla moral, dejar al lector en aquel anhelo doloroso y fecundo estado que lo lleve a descubrir cuál es su propio camino. Considera que lo esencial es despertar en los hombres la conciencia crítica; en la misma tradición de Sócrates convida: conócete a ti mismo, júzgate, entiéndete, si quieres conocer lo demás; lo demás se te dará por añadidura. Si cada uno sabe lo que de veras posee, que cada uno se encargue de cuidarlo. En este sentido, es verdad que el aprendizaje no está acabado a lo largo de nuestra existencia. Enuncia José Enrique Rodó: “Mientras vivimos, nada hay en nosotros que no sufra retoque y complemento. Todo es revelación, todo es enseñanza, todo es tesoro oculto, en las cosas; y el sol de cada día arranca de ellas nuevo destello de originalidad" (Los Motivos de Proteo, p. II). Lo que sigue es la necesidad de renovación de las propias facultades intelectuales y morales.

En la Cartilla moral, Reyes busca comprender el conjunto de normas, preceptos y valores morales aplicables a nuestra sociedad. La bondad solo resulta de una voluntad infatigable hacia el bien y lo único que puede enseñarse es el camino, el rumbo, el recelo contra la mentira propia o ajena, consciente o inconsciente. No puede darse actitud más pura y más absolutamente crítica. Ello explica, en parte, las reacciones adversas contra Reyes y su obra, por parte de aquellos a quienes el mucho interrogarse no dejaría vivir en paz. La censura y desprecio del que ha sido objeto la Cartilla desde su creación en 1944 es en cierta forma una venganza contra el humanismo y la civilidad.

La lectura de la edición de la Cartilla moral a cargo de Javier Garciadiego, “a nadie hará daño y resultarán beneficiados los que la lean” (2019, p. 65); pues si juzgamos al árbol por sus frutos, al hombre por su conducta y aún por los discípulos que formó, resulta inútil preguntarse si Alfonso Reyes alcanzó o no alcanzó a reflexionar una noción del bien en provecho de la humanidad. 


\section{Referencias}

Exposición de motivos y texto de la Ley que establece la Campaña Nacional contra el Analfabetismo, expedida por el Presidente Manuel Ávila Camacho el 21 de agisto de 1944, Diario Oficial, México 23 de agosto de 1944. (1984). En T. Carbó, Educar desde la Cámara de Diputados. Centro de Investigaciones y Estudios Superiores en Antropología Social.

Garciadiego, J. (2019). La Cartilla moral: vicisitudes editoriales y posibilidades políticas. En A. Reyes, La Cartilla moral. El Colegio Nacional.

Gobierno de México. (20 de marzo de 2019). Secretaría de Educación Pública del Gobierno de México. https://www.gob.mx/sep

Hornedo Rocha, B. (2019). Los primeros 75 años de la Cartilla moral de Alfonso Reyes. En prensa.

INEGI. (17 de marzo de 2019). Sexto censo de población 1940. https://www.inegi.org.mx/ programas/ccpv/1940/

Reyes, A. (1967). Universidad, política y pueblo. (J. E. Pacheco, Ed.). UNAM.

Reyes, A. (1997). Atenea política. En Obras completas XI. FCE.

Reyes, A. (1997). Esta hora del mundo. En Obras completas XI. FCE.

Reyes, A. (1997). Posición de América. En Obras completas XI. FCE.

Reyes, A. (2013). Diario 1945-1951. (V. D. Arciniega, Ed.). FCE.

Reyes, A. (2015). Diario 1951-1959. (F. Curiel Defosé, B. Clark de Lara, \& L. A. Viveros Anaya, Edits.). FCE.

Reyes, A. (2018). Diario 1939-1945. (J. Garciadiego, Ed.). FCE.

Reyes, A. (2019). Cartilla moral. (J. Garciadiego, Ed.). El Colegio Nacional.

Rodó, J. E. (3 de marzo de 2019). Los Motivos de Proteo. Biblioteca Virtual Miguel de Cervantes: http://www.cervantesvirtual.com/obra-visor/motivos-de-proteo--o/ html/fefcc83a-82b1-11df-acc7-002185ce6064.html

Torres Bodet, J. (2017). Memoria I. Tiempo de arena/ Años con el tiempo/ La victoria sin alas. FCE.

Vasconcelos, J. (1923). Invitación a los intelectuales y maestros para que se inscriban como misioneros. En Boletín de la Secretaría de Educación Pública (pp. 177-178). Secretaría de Educación Pública. 
